Document downloaded from:

http://hdl.handle.net/10251/98645

This paper must be cited as:

Corral Hernandez, JA.; J. Antonino-Daviu; Pons Llinares, J.; Climente Alarcon, V.; FrancésGaliana, V. (2015). Transient-Based Rotor Cage Assessment in Induction Motors Operating With Soft Starters. IEEE Transactions on Industry Applications. 51(5):3734-3742. doi:10.1109/TIA.2015.2427271

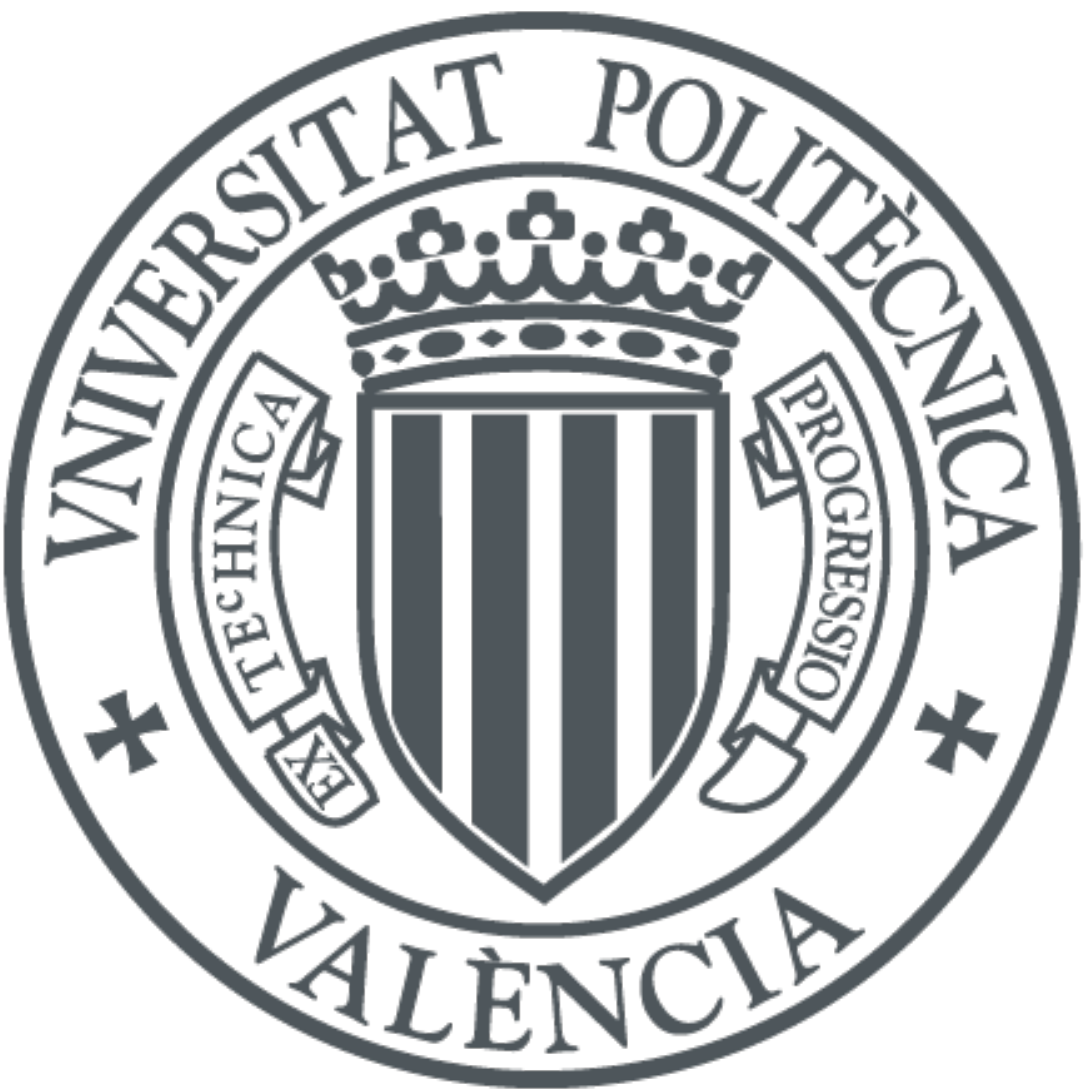

The final publication is available at

http://doi.org/10.1109/TIA.2015.2427271

Copyright Institute of Electrical and Electronics Engineers

Additional Information 


\section{Transient-based rotor cage assessment in induction motors operating with soft-starters}

\author{
Jesus A. Corral-Hernandez, Jose Antonino-Daviu, \\ Joan Pons-Llinares, Vicente Frances-Galiana \\ Universitat Politecnica de València \\ Institute for Energy Engineering \\ Camino de Vera s/n, 46022 Valencia, SPAIN \\ jecorher@doctor.upv.es, joanda@die.upv.es
}

\author{
Vicente Climente-Alarcon \\ Department of Electrical Engineering and Automation, \\ Aalto University, \\ P. O. Box 13000 , \\ FI-00076 Aalto, FINLAND \\ viclial@ieee.org
}

\begin{abstract}
The reliable assessment of the rotor condition in induction motors is a matter of increasing concern in industry. Though rotor damages are more likely in line-started motors operating under high inertias, some cases of broken rotor bars in motors supplied via soft-starters have been also reported in the industry. Motor Current Signature Analysis (MCSA) is the most widely spread approach to diagnose such failures. However, its serious drawbacks in many real industrial applications have encouraged the investigation on alternative methods enhancing the reliability of the diagnosis. This paper extends a recently introduced diagnosis methodology relying on the startup current analysis to the case of soft-starter-operated motors. The approach has proven to provide very satisfactory results, even in cases where the classical MCSA does not lead to correct diagnosis conclusions. However, its extension to operation under soft-starters was still a pending issue. The experimental results shown in this paper ratify the validity of the proposed diagnosis approach in soft-starter-operated induction motors.
\end{abstract}

\section{INTRODUCTION}

Cage induction motors participate in a huge number of industrial processes and applications [1]. Though they are robust machines, their extensive utilization together with the severe repercussions of their eventual failures have justified the effort in the development of reliable techniques able to detect possible faults, when these are still in early stages [2].

According to several general surveys, rotor failures amount for approximately $10 \%$ of the faults taking place in these machines [1]. Despite this is not a huge occurrence rate, these failures are more likely in large motors with heavy startups and operating under demanding duty cycles and high inertias. Under these conditions, the heat dissipated in the rotor cage leads to temperature gradients that facilitate the occurrence of the fault [3]. These large motors are usually the most critical, expensive and difficult to repair. These facts, among other, have justified the vast amount of studies devoted to this specific fault.

In the industry, the classical method to assess the rotor condition is based on the application of the classical Motor Current Signature Analysis (MCSA) [1]. MCSA is also the method implemented in the few commercially available induction motor condition monitoring devices. Synthesizing, MCSA relies on evaluating the amplitude of certain frequency components in the FFT spectrum of the steadystate current that are linked to the failure. The most commonly used components for rotor condition assessment are known as 'sideband harmonics' (SHs); they appear at both sides of the fundamental frequency at frequencies given by (1) (Lower Sideband Harmonic (LSH) with negative sign in (1) and Upper Sideband Harmonic (USH) with positive in (1), with $f=$ supply frequency and $s=$ slip) [1].

$$
f_{S H}=f \cdot(1 \pm 2 \cdot s)
$$

Despite MCSA has important advantages in comparison with other techniques when assessing the rotor condition (simplicity, non-invasive nature, possibility of quantification of the fault severity), it has some important drawbacks that have been recently extensively reported in the literature [4-6]. The most important constraint is linked to the fact that, due to the inherent nature of the FFT, MCSA application is only strictly suitable for machines operating under pure steadystate conditions. However, when this premise is not fulfilled (e.g., applications where the machine load continuously changes (sewage treatment plants, compressors or coal mills in thermal plants, giant bucket wheel stone excavators ...) or variable speed applications (pumps, machine tools, conveyor belts...) [7-8]), MCSA may significantly fail.

Other drawbacks related to MCSA application rely on the lack of reliability in certain situations where its application may lead to false diagnostics (either to false positives or false negatives). For instance, the presence of some external phenomena such as load torque oscillations or supply voltage fluctuations [4-5] or even certain constructive characteristics of the machine (presence of cooling axial ducts when number of ducts $\left(N_{d}\right)$ is equal to number of machine poles $\left(N_{p}\right)$ [9-10] and magnetic core anisotropy issues [11]) are likely to introduce components in the FFT spectrum with frequencies that are identical to those of the SHs, a fact that may lead to false positive rotor fault indications. On the other hand, when MCSA is applied to machines under no-load conditions, the SHs may not be discernible, even if the machine is faulty, due to the reduced value of the slip (false negative) [5,12]. Also, in the event of broken outer bars in double cage motors the MCSA may not show significant increments in the SHs amplitudes, since most of the current is confined in the inner cage in steady-state, a fact that may eventually lead to false negative diagnostics of the fault $[6,13]$.

To overcome the aforementioned constraints of MCSA, alternative diagnosis methodologies have been developed. Among them, a new trend that has drawn a significant 
attention is based on extending the analysis to any possible operation regime of the machine (rather than limiting the study to steady-state). The idea is to analyze the corresponding quantity regardless of the operation regime of the machine, including transients [5, 12-18]. In this context, the analysis of the startup current has been proposed by several authors [5, 12-13]; the underlying idea of many startup-current-based techniques relies on tracking the timefrequency evolutions of fault related components during the startup (unlike the MCSA in which only frequency peaks are identified in the FFT spectrum). Such characteristic transient evolutions can only be caused by the corresponding failure, a fact that increases the reliability of the diagnostic. The problem is that, to obtain such evolutions, advanced signal processing tools that are able to provide a time-frequency representation of the analyzed signal (star-up current) must be used; These are known as Time-Frequency Decomposition (TFD) tools and there is a wide variety of these tools that can be used [7, 19-24]. The application of these tools leads to t-f maps where very characteristic patterns created by the evolutions of fault components (when present) can be identified. These patterns are very reliable indicators of the presence of the fault, since it is very unlikely that other phenomena may lead to similar patterns. Moreover, the fault severity can be quantified based on the energy in certain regions of the t-f map $[5,12,19]$.

Among the possible TFD tools that are suitable to analyze the startup current, the Discrete Wavelet Transform (DWT) has some inherent advantages [5, 19]: its simplicity, its low computational requirements, the easy interpretation of its results and the possibility of introducing fault severity indicators, among other, have motivated its extensive use for transient-based fault diagnosis.

Despite the startup-current-based methodology has been validated in machines with diverse constructive characteristics and operating under different duty cycles $[5,8$, $12-13,19]$, its validity in soft-starter-operated machines is still a pending issue. One of the reasons for the lack of works in this area is the common assumption that the use of softstarters prevents from the occurrence of rotor damages; this has been proven to be uncertain as revealed by real field cases that have reported the presence of rotor faults in motors operated with such elements. The occurrence of rotor faults in soft-started motors can be justified by the fact that softstarters do not avoid the eventual appearance of relatively high-starting currents (several times the rated current) during long starting periods, especially if the programming of the soft-starter options is deficient and is not suited to the motor characteristics and/or the particular application where it operates. Hence, the study of eventual rotor faults under softstarter operation is a matter of interest despite the few existing publications that deal with this topic [15].

This paper extends the proposed transient-based technique to induction motors operating under soft-starters. The DWT is used as TFD tool. The results of the laboratory and field tests included in this paper prove the validity of the approach, since the characteristic fault-related patterns clearly appear and, in addition, it is possible to define fault severity indicators relying on the energy of the resulting DWT signals.

\section{BACKGROUND}

\section{A. DWT}

The $n$-level DWT of a certain sampled signal $i(t)$ performs the decomposition of that signal onto a set of wavelet signals: an approximation signal $a_{n}$ and a set of detail signals $d_{1}, d_{2}$, $d_{3} \ldots d_{n}$ [25]. The idea underlying the decomposition process is the next one: each wavelet signal is associated with a predefined frequency band that depends on the sampling rate $f_{s}$ and on the level of the corresponding wavelet signal. The expressions relating each wavelet signal with its associated frequency band are well-known and are detailed in Table I (an example for a specific $f_{s}$ is also provided in that Table). To sum up, the DWT performs a band-pass filtering of the signal $i(t)$, each wavelet signal containing the time evolution of all frequencies included within its associated band.

TABLE I

DWT SIGNALS: ASSOCIATED FREQUENCY BANDS AND EXAMPLE

\begin{tabular}{|c|c|c|c|}
\hline Wavelet signal & Frequency band & \multicolumn{2}{|c|}{ Example: $\boldsymbol{f}_{s}=\mathbf{1 0 0 0 0} \mathbf{H z}, \boldsymbol{n}=\mathbf{8}$} \\
\hline$a_{n}$ & {$\left[0,2^{-(\mathrm{n}+1)} \cdot f_{s}\right]$} & $a_{8}$ & {$[0-19.5] \mathrm{Hz}$} \\
\hline$d_{n}$ & {$\left[2^{-(\mathrm{n}+1)} \cdot f_{s}, 2^{-(\mathrm{n})} \cdot f_{s}\right]$} & $d_{8}$ & {$[19.5-39] \mathrm{Hz}$} \\
\hline$d_{n-1}$ & {$\left[2^{-(\mathrm{n})} \cdot f_{s}, 2^{-(\mathrm{n}-1)} \cdot f_{s}\right]$} & $d_{7}$ & {$[39-78] \mathrm{Hz}$} \\
\hline$\ldots$ & $\ldots$ & $\ldots$ & $\ldots$ \\
\hline$d_{3}$ & {$\left[2^{-4} \cdot f_{s}, 2^{-3} \cdot f_{s}\right]$} & $d_{3}$ & {$[625-1250] \mathrm{Hz}$} \\
\hline$d_{2}$ & {$\left[2^{-3} \cdot f_{s}, 2^{-2} \cdot f_{s}\right]$} & $d_{2}$ & {$[1250-2500] \mathrm{Hz}$} \\
\hline$d_{l}$ & {$\left[2^{-2} \cdot f_{s}, 2^{-1} \cdot f_{s}\right]$} & $d_{l}$ & {$[2500-5000] \mathrm{Hz}$} \\
\hline
\end{tabular}

\section{B. The method}

The proposed approach relies on analyzing the startup current. Unlike what happens in steady-state, where the fault components frequencies are well defined, during the transient, these frequencies change over time, following wellcharacterized evolutions that depend on the fault $[5,12]$. As commented, these evolutions lead to very reliable patterns that can be used to diagnose the presence of the corresponding failure. For instance, in the event of broken bars, during a direct startup, as the slip $s$ changes between 1 and near 0 , the LSH time-frequency evolution leads to a very characteristic $\Lambda$-shaped pattern that can be used to diagnose the failure (see (1)) [5]. This characteristic evolution is reflected through the oscillations appearing in the DWT signals (that are, indeed, time-frequency representations of the analyzed current). As an example, Fig. 1 (a) and (b) illustrate, respectively, the DWT for a healthy machine and for a machine with two broken rotor bars (only the high-order wavelet signals are depicted). The differences are evident, rising, in the latter case, a clear $\Lambda$-shaped pattern associated with the breakage. The advantage is that this pattern is very reliable; it appears only when a bar breakage is present, since no other cause (load torque oscillations, cooling ducts...) leads to a similar pattern $[5,12]$. On the other hand, the pattern appears regardless of the loading condition of the machine so it also appears in unloaded machines [5].The detection of the aforementioned qualitative patterns must come together with a quantification of the level of failure in the machine. To this end, several quantification indicators 
have been proposed in the past. They are based on the results of the signal processing tools commented above. One of the proposed indicators, relying on the DWT, is given by (2). In expression (2), $i_{j}$ is the value of the $j$ th sample of the current signal; $d_{n f+l}(j)$ is the $j$ element of the detail of order $n f+1$ ( $n f=$ order of the signal containing the fundamental); $N_{s}$ is the number of samples of the signal, until reaching the steadystate regime and $N_{b}$ is the number of samples between the origin of the signals and the extinction of the oscillations due to border effect [12].

Synthesizing, this indicator relates the energy of the total startup current signal (i) with that of the DWT signal containing most of the fault component evolution $(d)$. In agreement with its definition, the higher the value of the indicator $\gamma_{D E}$, the lower the energy of the $d$ signal and, hence, the healthier the machine is.

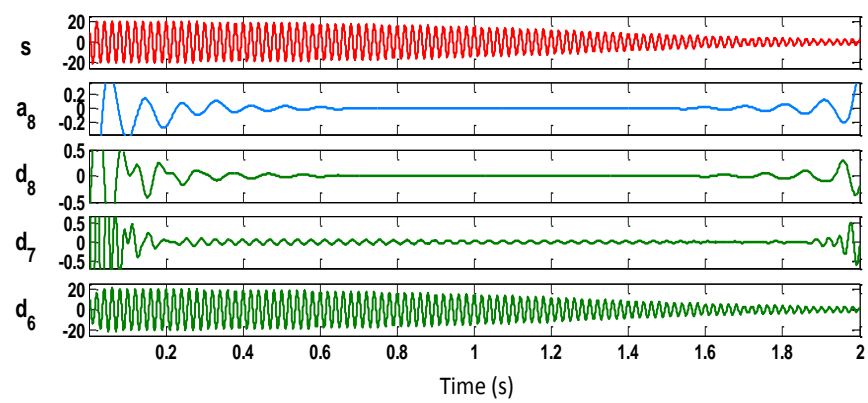

(a)

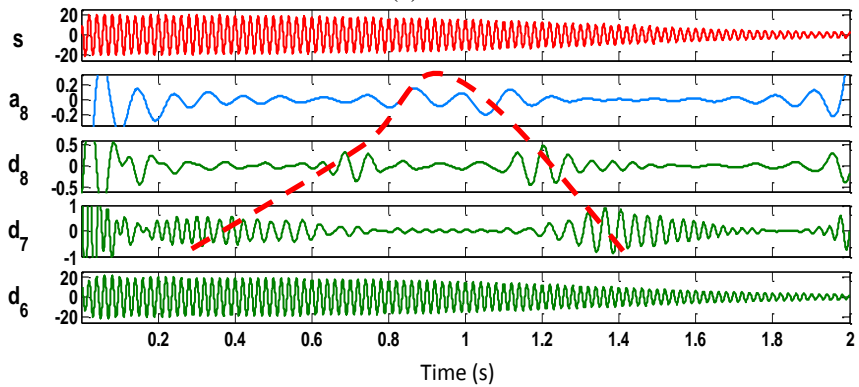

(b)

Fig. 1 DWT of the startup current for: (a) healthy machine, (b) machine with 2 broken bars.

$$
\gamma_{D E}(d B)=10 \cdot \log \left[\frac{\sum_{j=N b}^{N s} i_{j}^{2}}{\sum_{j=N b}^{N s}\left[d_{n f+1}(j)\right]^{2}}\right]
$$

\section{EXPERIMENTS}

Both laboratory and field tests were developed to confirm the validity of the proposed approach for the case of softstarted motors. While the tested laboratory motors were small machines (rated $1,1 \mathrm{~kW}$ ), the considered field motors had larger sizes $(265 \mathrm{~kW})$. This enabled to validate the generality of the proposed method.

In all tests (laboratory and field experiments), the stator startup currents were recorded by means of a commercial waveform recorder. All signals were captured at a sampling rate $f_{s}=5 \mathrm{kHz}$. Once recorded, the signals were transferred to a computer. The DWT was applied to each signal using $n=8$ decomposition levels and dmeyer as mother wavelet. In agreement with the theoretical explanations of Section II.A, for the sampling rate employed, the approximate frequency bands associated with each wavelet signal are the ones specified in Table II (only the high level signals are displayed). Hence, during the startup, the whole evolution of the fundamental component $(50 \mathrm{~Hz})$ should be contained in signal d6, while the LSH should successively evolve through the signals d6-d7-d8-a8, as its frequency decreases first from $50 \mathrm{~Hz}$ to $0 \mathrm{~Hz}$, and again through a8-d8-d7-d6, as its frequency increases again towards $50 \mathrm{~Hz}$, raising the characteristic pattern depicted in Fig. 1(b).

TABLE II

FREQUENCY BANDS COVERED BY HIGH LEVEL DWT SIGNALS

\begin{tabular}{|c|c|}
\hline Wavelet signal & App. Frequency band \\
\hline $\mathrm{a} 8$ & {$[0 \sim 9] \mathrm{Hz}$} \\
\hline $\mathrm{d} 8$ & {$[9 \sim 19] \mathrm{Hz}$} \\
\hline $\mathrm{d} 7$ & {$[19 \sim 39] \mathrm{Hz}$} \\
\hline $\mathrm{d} 6$ & {$[39 \sim 78] \mathrm{Hz}$} \\
\hline
\end{tabular}

\section{A. Laboratory Tests}

Laboratory experiments were developed using single cage $1,1 \mathrm{~kW} \mathrm{Al}$ die cast induction motors with different levels of failures. The rated characteristics of each of these motors are displayed in Table III. In each test, the motor was coupled to a DC machine acting as a load.

The motor was supplied through a Siemens Sikostart 3RW22 soft-starter. This is a three-phase full-wave controlled soft starter; the phase control is implemented in all three phases. Two back-to-back thyristors are used as power semiconductors. The line terminals are connected to the three thyristor blocks of the soft-starter that control the voltage applied to the motor windings. Fig.2 shows the standard connection in the case of a motor with its windings in star configurations. The soft starter is connected in series with the motor windings. In this soft-starter, several parameters could be easily customized by the user: initial value of the applied voltage ramp, duration of the startup or maximum value for the startup current. The modification of these parameters enables to perform startups under different modalities (voltage ramp startup and/or current limitation).

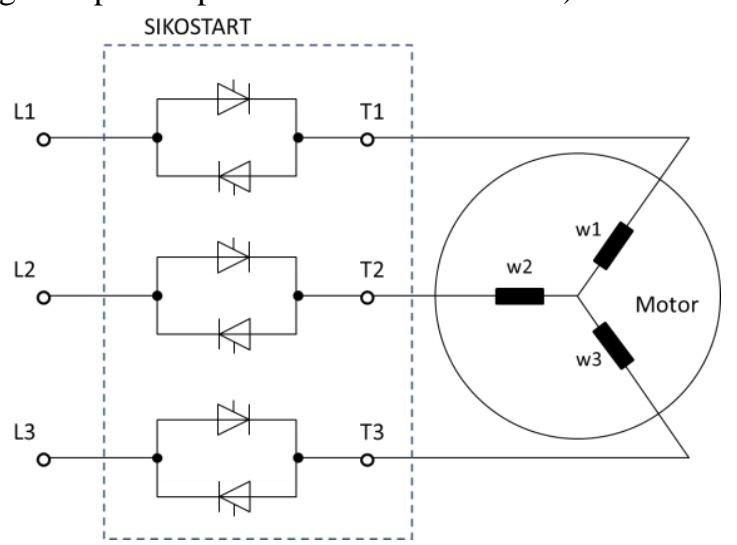

Fig. 2 Schematic representation of the thyristor-based soft-starter and its connection to the motor. 
Several startups were carried out under the different softstarter modalities for induction motors with various faulty conditions (healthy, one broken bar and two adjacent broken bars). The breakages were artificially forced in the laboratory by drilling a hole in the junction point between the corresponding bar and the short-circuit end-ring.

Fig. 3 shows pictures of the whole test-bed as well as of the soft-starter and faulty rotor that were employed during the laboratory experiments.

TABLE III

RATED CHARACTERISTICS OF THE $1,1 \mathrm{KW}$ MOTOR

\begin{tabular}{|l|c|}
\hline Rated Power & $1.1 \mathrm{~kW}$ \\
\hline Rated frequency & $50 \mathrm{~Hz}$ \\
\hline Rated Voltage & $400 \mathrm{~V}$ \\
\hline Rated primary current & $2.7 \mathrm{~A}$ \\
\hline Rated speed & $1410 \mathrm{rpm}$ \\
\hline Rated slip & 0.06 \\
\hline Connection & Star \\
\hline Number of pole pairs & 2 \\
\hline Number of rotor bars & 28 \\
\hline Number of stator slots & 36 \\
\hline
\end{tabular}

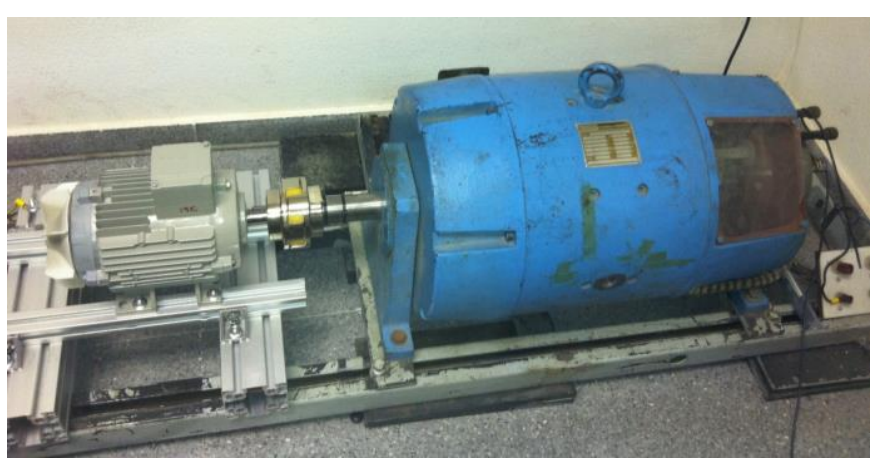

(a)

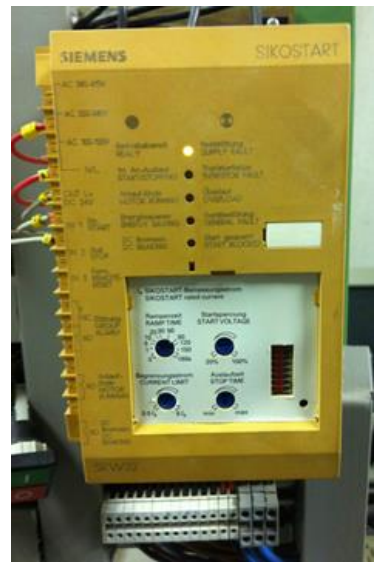

(b)

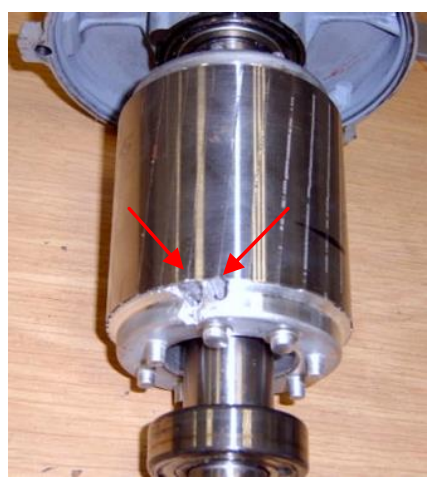

(c)
Fig. 3. Photos of: (a) laboratory test bench, (b) soft-starter employed for laboratory experiments and (c) tested faulty rotor.

\section{B. Field Tests}

Field tests were also developed in two pump motors (M1 and M2) that were operating in a sewage treatment plant. These motors had identical characteristics and were driven by soft-starters (see Fig. 4). Both motors were started under the current limitation option (in the case of M2 combined with voltage ramp). The details of both motors are provided in Table IV. The starting current signals were captured in the motor switchboard using the waveform recorder as well as current clamps suited for those machines (see Fig. 4).

TABLE IV

\section{RATED CHARACTERISTICS OF THE TWO FIELD MOTORS}

\begin{tabular}{|l|c|}
\hline Rated Power & $265 \mathrm{~kW}$ \\
\hline Rated frequency & $50 \mathrm{~Hz}$ \\
\hline Rated Voltage & $400 \mathrm{~V}$ \\
\hline Number of poles & 10 \\
\hline
\end{tabular}
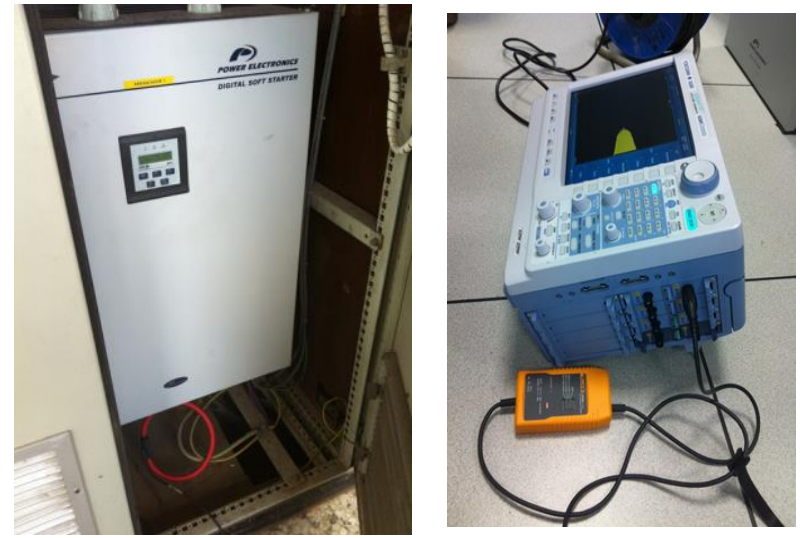

Fig. 4. Details of the field tests: soft-starter, current clamp and waveform recorder.

\section{RESULTS AND DISCUSSION}

\section{A. Laboratory Tests}

Fig. 5 shows the high level wavelet signals resulting from the application of the DWT to the startup current for the linestarted healthy motor (Fig. 5(a)) and for the healthy motor started with soft-starter (Figs. 5(b) and (c)). In Fig. 5 (b), the soft-starter was set up so that a voltage ramp was applied to the motor during the startup (initial voltage $=30 \%$ of rated voltage and startup length $=7.5 \mathrm{~s}$ ) with the current limiting option not activated. In Fig. 5(c) the motor was started under the same conditions but adding a current limiting condition (maximum current $=2$ ' 5 - rated current). Figs. 6 are analogue but for the motor with two broken bars. The detailed waveforms of the voltages and currents at the motor terminals during the three starting cases are depicted in Fig.7.

The differences between Figs. 5 and 6 are evident. In Fig. 6 , clear oscillations are observed in the wavelet signals. These oscillations fit the characteristic pattern caused by the timefrequency variation of the LSH during the startup. Moreover, the pattern appears, not only in the case of direct startup (Fig. 6 (a)), but also for the cases using soft-starter (Fig. 6 (b) and (c)). On the other hand, the pattern is totally absent in the case of healthy machine (Fig. 5) for any startup modality; it is not present either in the direct startup or for the case of using soft-starter. This fact seems to confirm the validity of the methodology when it is extended for the case of soft-started motors. Computation of severity indicators ratifies this idea. 


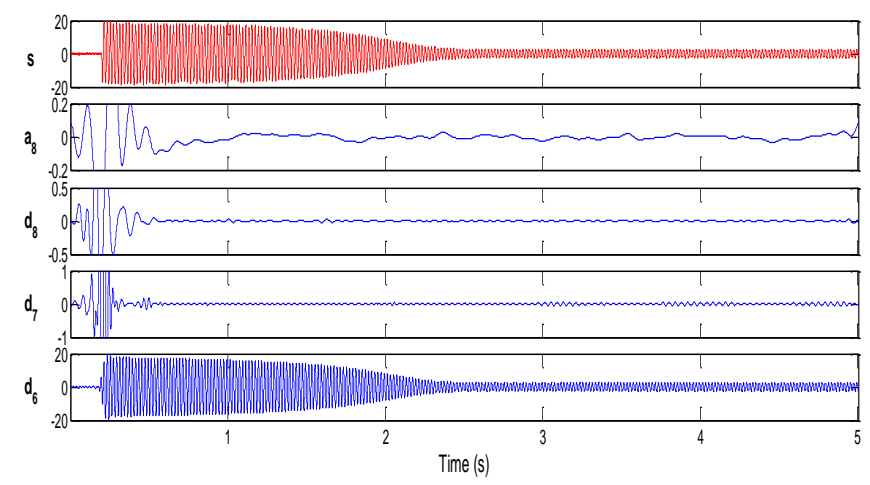

(a)

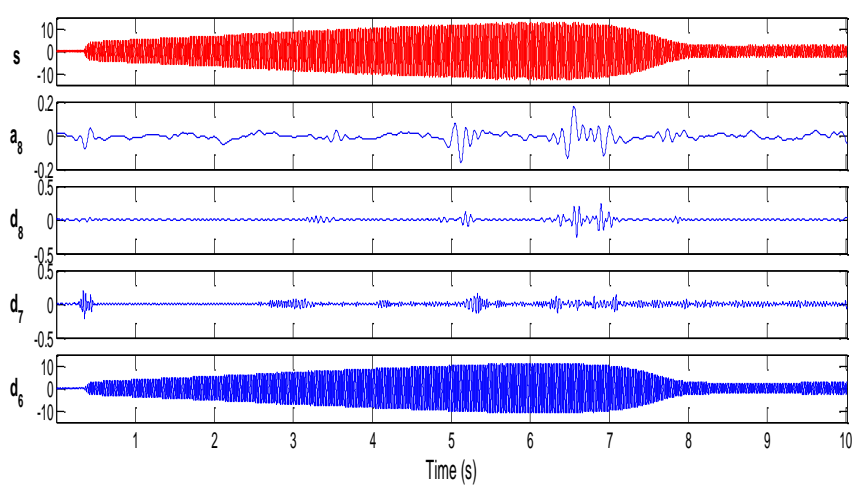

(b)

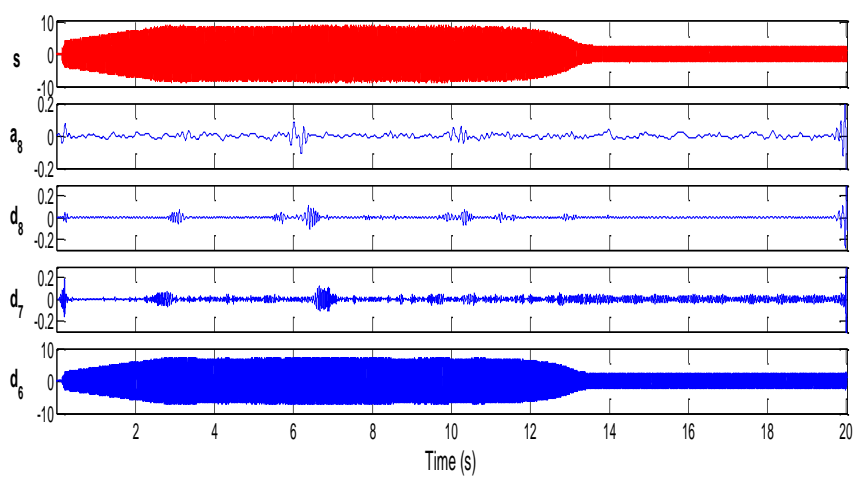

(c)

Fig. 5 DWT of the startup current for the healthy motor: (a) line-started, (b) started with soft-starter (voltage ramp) and (c) started with soft-starter (voltage ramp+current limitation).

Table $\mathrm{V}$ shows the results of the computation of the fault severity indicator $\gamma_{D E}$ for the different cases depicted in Figs. 5 and 6. Clear differences are observed in the value of the fault indicator between healthy and faulty conditions for each startup method. Moreover, it is especially remarkable how the indicator remains within a narrow band for a certain faulty condition, regardless of the startup method (direct on-line startup or startup with soft-starter (current limitation and voltage ramp)). The slight differences detected for different startup methods are caused by the harmonics introduced by the soft-starter that lead to oscillations in the wavelet signals even in healthy condition (see Fig. 5 (b) and (c)), a fact that

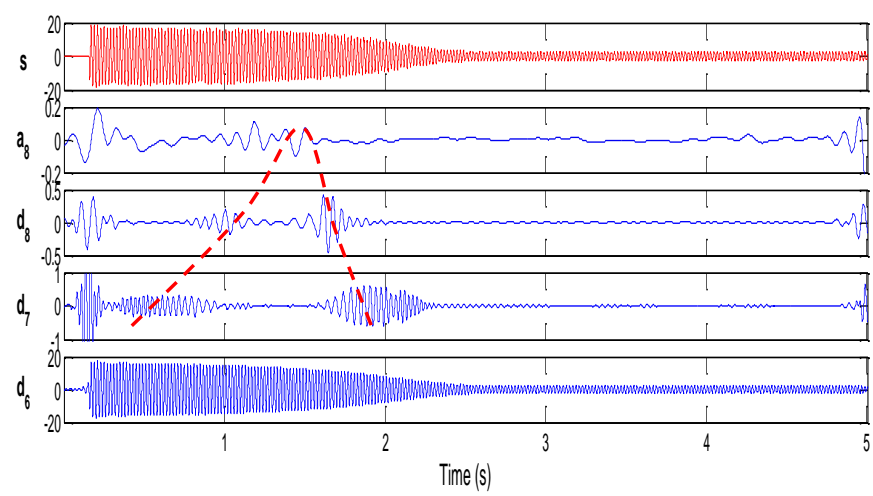

(a)

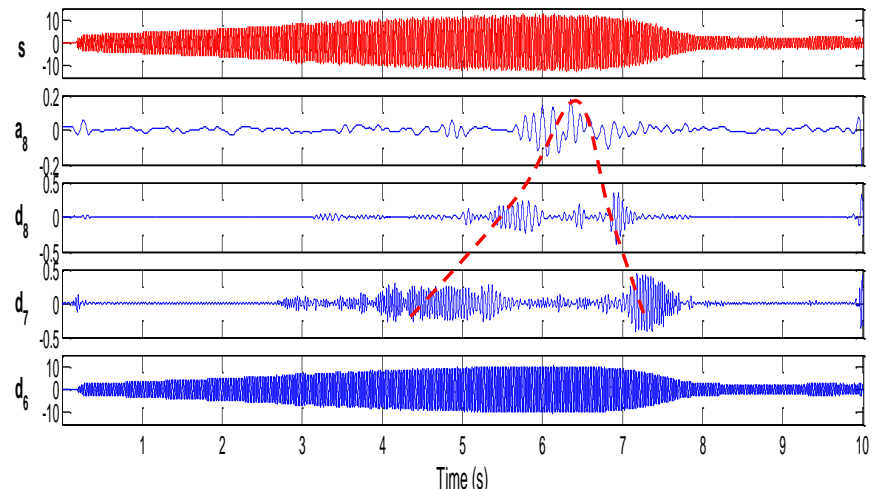

(b)

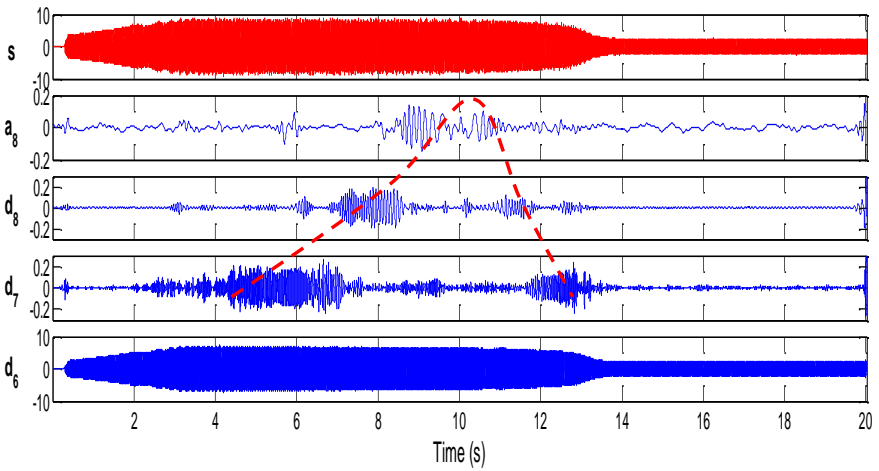

(c)

Fig. 6 DWT of the startup current for the motor with two broken bars and: (a) line-started, (b) started with soft-starter (voltage ramp) and (c) started with soft-starter (voltage ramp+current limitation).

reduces the sensitivity of the indicator. This issue is analyzed in detail in Section IV.C.

TABLE V

COMPUTATION OF FAULT INDICATOR $\gamma_{D E}$ FOR THE LABORATORY TESTS

\begin{tabular}{ccc}
\hline Startup method & Condition & $\begin{array}{c}\text { Fault } \\
\text { indicator } \gamma_{D E}\end{array}$ \\
\hline Line-started & Healthy & 51.5 \\
Sort-starter (voltage ramp) & Healthy & 44.2 \\
Soft-starter (current limitation + & Healthy & 45.2 \\
voltage ramp) & 2 broken bars & 28.3 \\
Line-started & 2 broken bars & 30.3 \\
Sort-starter (voltage ramp) & 2 broken bars & 35.3 \\
Soft-starter (current limitation + & & \\
voltage ramp) & &
\end{tabular}


(a)
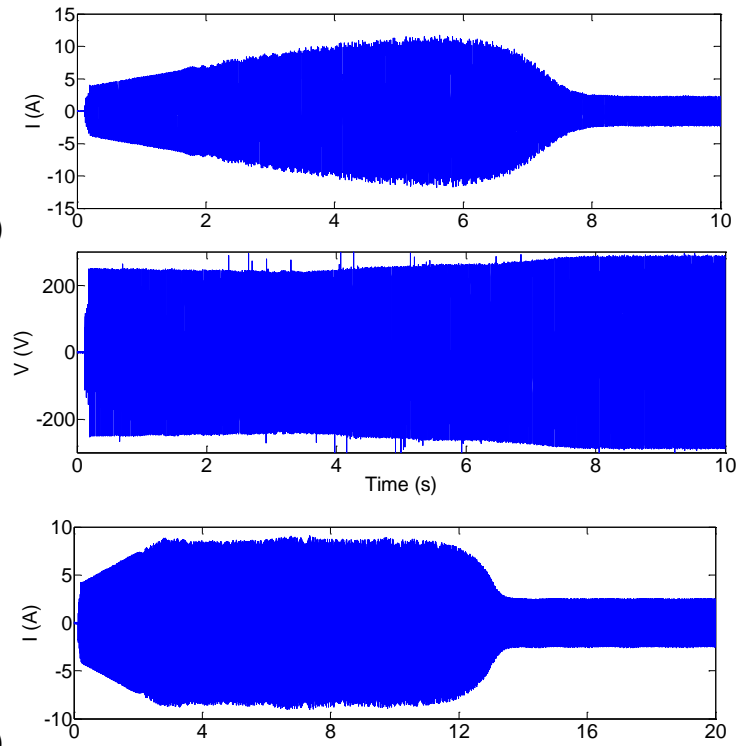

(b)
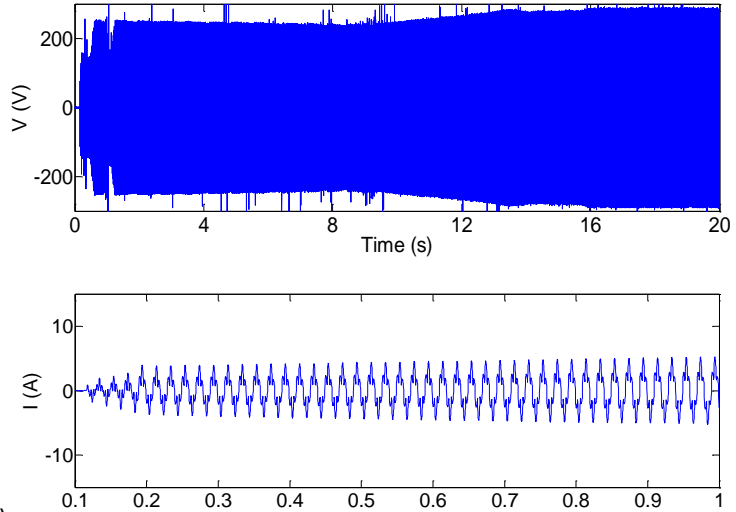

(c)

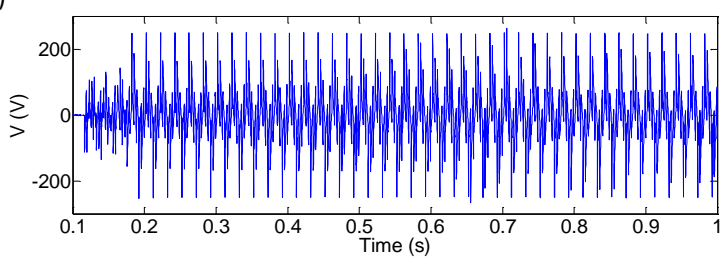

Fig. 7 Waveforms of the voltage (top) and current (bottom) at the motor terminals for: (a) motor started with soft-starter (voltage ramp), (b) motor started with soft-starter (voltage ramp+current limitation), (c) zoomed waveforms during the initial 0'5 sec.

\section{B. Field Tests}

Figs. 8 (a) and (b) show the high level wavelet signals resulting from the DWT of the startup current for the two soft-started field motors (their characteristics were specified in Table IV). Note that, as commented above, both motors were started using the current limitation option (in the case of M2 combined with voltage ramp). Interestingly, for the first motor (M1) (Fig.8 (a)), no fault pattern is observed in the high-level wavelet signals. Moreover, the computation of the fault severity indicator, given by (2), yields a very high value for this specific motor (see Table VI) that is higher than 50 $\mathrm{dB}$. This indicates the healthy condition of the rotor cage for this machine.
On the other hand, Fig. 8 (b) shows the DWT analysis for the second motor (M2) revealing the presence of a clear Vshaped pattern in the high-level signals that is similar to the one observed for the laboratory motors. The computation of the fault indicator $\gamma_{D E}$ confirms the damage in the rotor cage since this indicator has a value below $40 \mathrm{~dB}$, much lower than that of the motor M1 (see Table VI). This indicates the faulty condition of the rotor cage.

Note that these results are in concordance with those obtained for these motors if using the classical MCSA, despite in this case the application of this classical method is much more difficult since these motors operated under reduced load conditions (low slip) and, hence, the detection of the sideband harmonics is complicated [5].

\section{$s$}

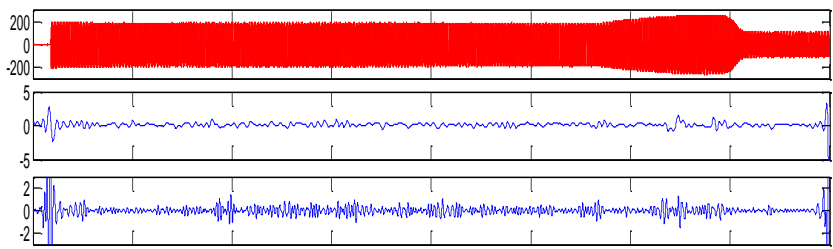

$d_{7}$ 2 . 2 .

4.

(a)

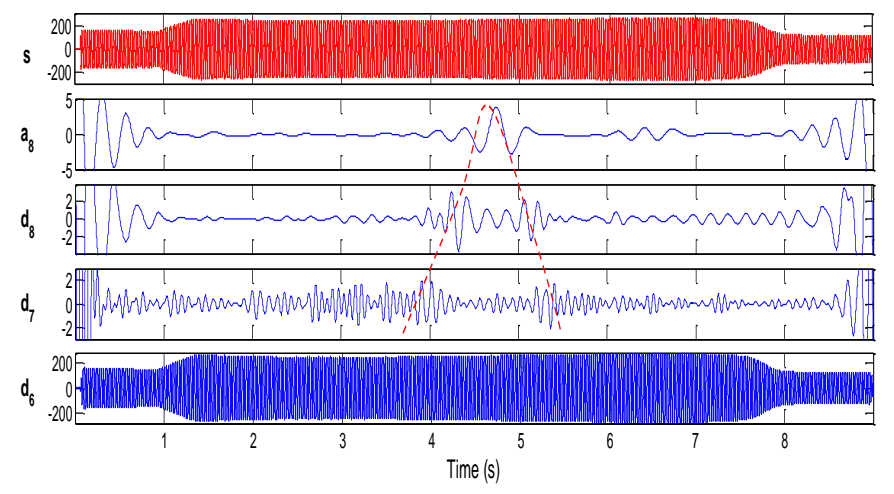

(b)

Fig. 8 DWT of the startup current for the two field soft-started motors: (a) M1 (current limitation) and (b) M2 (voltage ramp).

TABLE VI

COMPUTATION OF FAULT INDICATOR $\gamma_{D E}$ FOR THE FIELD MOTORS

\begin{tabular}{ccc}
\hline Motor & $\begin{array}{c}\text { Fault indicator } \\
\gamma_{D E}\end{array}$ & $\begin{array}{c}\text { Diagnosis } \\
\text { conclusion }\end{array}$ \\
\hline M1 & 52.38 & Healthy \\
M2 & 32.16 & Faulty
\end{tabular}

C. Brief analysis of the components introduced by the soft-starter and their effects on the wavelet signals

It is known that soft-starters produce harmonics during start. Usually, the harmonics are only produced during soft 
start and soft stop so appear for a very short period of time, unless the soft-starter has an energy saver function activated.

In a line-started healthy induction motor, the stator phase current has three main families of components [26]: the fundamental component (FC), the winding harmonics (WHs) and the principal slot harmonics (PSHs). While the WHs have fixed frequencies at odd multiples of the fundamental $\left(3^{\text {rd }}, 5^{\text {th }}\right.$, $\left.7^{\text {th }} \ldots\right)$, the PSHs are calculated according to (3) [26]:

$$
f_{P S H}=\left[k \cdot \frac{R}{p} \cdot(1-s) \pm v\right] \cdot f_{F C}
$$

Where $k$ is an integer number, $R=$ number of rotor slots, $p=$ number of pole pairs, $s=$ slip, $f_{F C}=$ fundamental frequency and $v=$ considered order of the supply voltage harmonic (odd number).

In a line-started motor, as the one the startup current of which is presented in Figs. 5(a) and 6(a), while the WHs remain at fixed frequencies during the startup, the frequencies of the PSHs change as $s$ does (between $s=1$ and $s=0$ ). The frequency evolutions of these PSHs over time in a direct startup were represented in detail in previous works using proper time-frequency tools [26].

The application of a time-frequency tool to the startup current of the motor considered in the present paper $(k=1$; $\left.R=28 ; p=2 ; f_{F c}=50\right)$ enables to observe the evolutions of these PSHs, as well as of the WHs during the startup (see Fig. 9 (a)). Note that the most important PSH for the case of linestarted motors is that obtained for $v=+1$ in (3), followed by those obtained for $v=-1, v=+3$ and $v=+5$ (note that the supply voltage in this laboratory test was not symmetrical, a fact that led to the appearance of PSHs that would not appear under symmetrical conditions). On the other hand, it is observed that the FC has very high amplitude in comparison with other WHs, being the $3^{\text {rd }} \mathrm{WH}$ still significant but having $5^{\text {th }}$ and $7^{\text {th }}$ much lower amplitudes for the line-started motor.

The application of the same time-frequency analysis to the startup current in the case of a soft-started motor reveals very different results., as shown in Fig. 9(b) (case of voltage ramp considered in the paper (healthy condition) (see Fig. 5(b))). The analysis shows a much higher presence of the WHs with orders 5 and 7. Also, it is interesting to observe the high amplitudes of many PSHs and, in particular, of the families with negative signs in (1), i.e., $v=-1, v=-3$ and $v=-5$. The frequencies of these harmonics drop to zero during the startup and increase afterwards until reaching their final steady-state values at higher frequencies. Indeed, it is the presence of this set of harmonics what provokes the energy increments in the wavelet signals (d7-d8-a8) even for healthy condition (see oscillations in wavelet signals depicted in Figs. 5(b) and (c)): since these wavelet signals cover altogether the frequency region [0-39 Hz] (see Table II), they are trespassed by this set of harmonics when their frequencies decrease to zero during the startup (see bottom of Fig. 9 (b)). Hence, the wavelet signals will show some oscillations when these PSHs penetrate within their covered band.

The conclusion is that, unlike a line-started machine, in the case of a soft-started motor, the low frequency region (0-50 $\mathrm{Hz}$ ) is much more 'polluted' due to the evolutions of PSHs with negative signs in (3), that have significant amplitudes for this starting method. Hence, the corresponding wavelet signals covering that frequency band will show relative increments in their energies, although the machine is in healthy condition. This explains the lower values of the fault indicator $\gamma_{D E}$ (that is inversely dependent on the wavelet signal energy) for a healthy soft-started motor in comparison with those obtained for a line-started motor (see Table V).

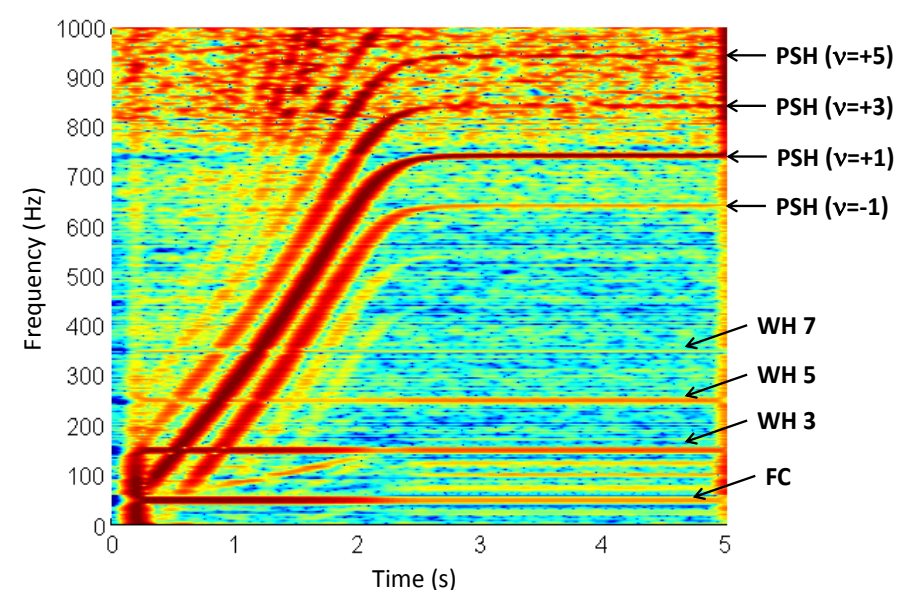

(a)

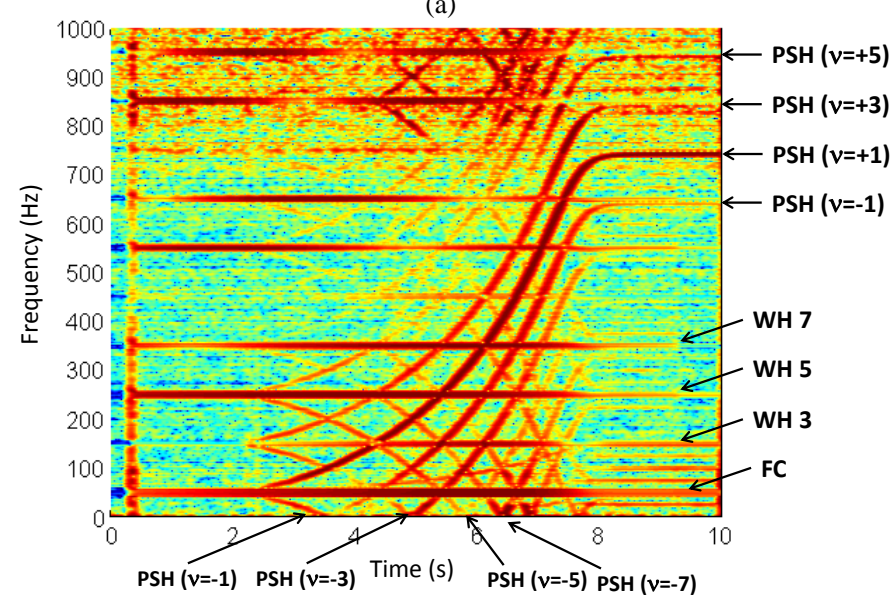

(b)

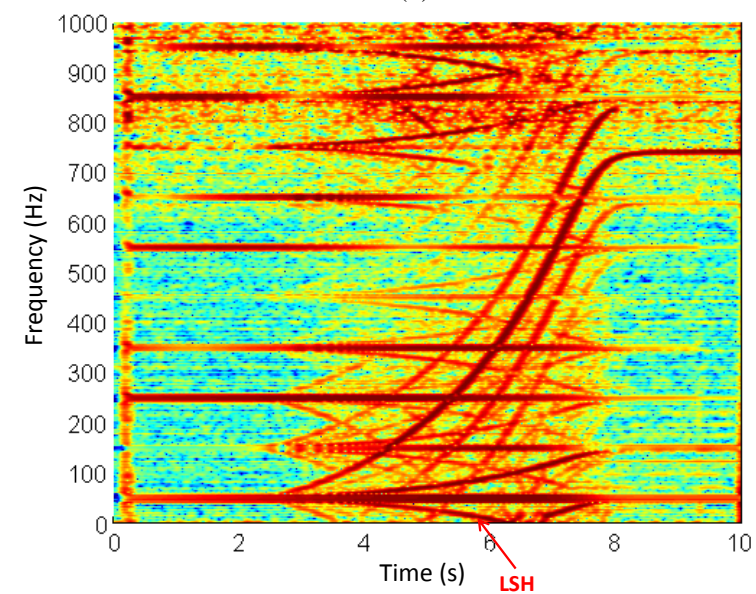

(c)

Fig. 9. Time-frequency analysis of the startup current for: (a) line-started motor (healthy condition), (b) soft-started motor supplied with a voltage ramp (healthy condition) and (c) soft-started motor supplied with a voltage ramp (two broken bars) 
When a rotor fault is present, the lower sideband will appear in that band (as well as other fault-related harmonics with lower amplitudes), as observed in Fig.9(c): this harmonic is clearly visible although it coexists with the aforementioned family of PSHs. Its presence will provoke logical increments of the energies of these signals, but the relative increase versus heathy condition will be lower than that for a line-started motor.

\section{CONCLUSIONS}

In this work, a recent bar breakage diagnosis methodology that relies on the analysis of transient quantities by means of advanced time-frequency decomposition tools is validated for the case of motors operating with soft-starters. The work focused on the analysis of the startup current signal by using the Discrete Wavelet Transform and on the further study of the resulting high-level wavelet signals to detect the characteristic pattern created by the evolution of the LSH, when the fault is present. The results included in the paper (coming both from laboratory tests as well as tests with field motors operating in a sewage treatment plant) show how the pattern clearly appears for the faulty machine operated with soft-started, while it is absent in healthy condition. Moreover, computation of a proposed fault severity indicator shows clear differences between its values for faulty and healthy conditions in every startup method. Slight variations between the value of the indicator for the different startup methods (line start vs. soft-start) and same faulty condition have been justified in the paper by analyzing the frequencies introduced by the soft-starter during the transient; the use of such elements yield significant increments in the amplitudes of the PSHs obtained for $v=-3, v=-5$ and $v=-7$ (among other), therefore increasing the energies if the wavelet signals affected by the evolution of these harmonics during the startup.

\section{ACKNOWLEDGMENT}

This work was supported by the Spanish 'Ministerio de Economía y Competitividad' (MINECO) in the framework of the 'Proyectos I+D del Subprograma de Generación de Conocimiento, Programa Estatal de Fomento de la Investigación Científica y Técnica de Excelencia' (ref: DPI2014-52842-P)."

\section{REFERENCES}

[1] W.T. Thomson, M. Fenger, "Current signature analysis to detect induction motor faults" IEEE Industry Applications Magazine, July/August 2001, pp. 26-34

[2] P. Zhang, Y. Du, T.G. Habetler, and B. Lu, "A Survey of Condition Monitoring and Protection Methods for Medium-Voltage Induction Motors," IEEE Transactions on Industry Applications, vol.47, no.1, pp.34,46, Jan.-Feb. 2011.

[3] J.M. Cubert, "Use of electronic controllers in order to increse the service life on asynchronous motors", Proc. European seminar on electro-technologies for industry, Bilbao, May 1992, pp.393-404

[4] R. R. Schoen and T.G. Habetler. "Evaluation and Implementation of a System to Eliminate Arbitrary Load Effects in Current-Based
Monitoring of Induction Machines," IEEE Trans. Ind. Appl., vol.33, no. 6, pp. 1571-1577, November/December 1997.

[5] J. A. Antonino-Daviu, M. Riera-Guasp, J. R. Folch, and M. Pilar Molina Palomares, "Validation of a new method for the diagnosis of rotor bar failures via wavelet transform in industrial induction machines," IEEE Trans. Ind. Appl., vol. 42, pp. 990-996, 2006.

[6] J. Park, B. Kim, J. Yang, K. Lee, S.B. Lee, E.J. Wiedenbrug, M. Teska, and S. Han, "Evaluation of the Detectability of Broken Rotor Bars for Double Squirrel Cage Rotor Induction Motors," in proc. of the IEEE ECCE, pp. 2493-2500, Sept. 2010.

[7] J. Pons-Llinares, V. Climente-Alarcón, F. Vedreño-Santos, J Antonino-Daviu, and M. Riera-Guasp, "Electric Machines Diagnosis Techniques via Transient Current Analysis, " in Proceedings of the 38th Annual Conference of the IEEE Industrial Electronics Society, IECON 2012, 25-28 October, 2012, Montreal, Canada.

[8] J. Antonino-Daviu,V. Climente-Alarcon, J. Pons-Llinares and E. Wiedenbrug, "Advanced rotor assessment of motors operating under variable load conditions in mining facilities," Proc. IEEE ECCE, pp. 617-621, Sep 2014.

[9] S. Lee, J. Hong, S.B. Lee, E. Wiedenbrug, M. Teska, and H. Kim, "Evaluation of the influence of rotor axial air duct design on condition monitoring of induction motors," IEEE Trans. on Ind. Appl., vol. 49, no. 5, pp. 2024-2033, Sept./Oct. 2013.

[10] Yang, T-J. Kang, D. Hyun, S. Lee, J. Antonino-Daviu, J. Pons-Llinares, "Reliable Detection of Induction Motor Rotor Faults Under the Rotor Axial Air Duct Influence," IEEE Trans. Ind. Appl., vol. 50, no. 4, pp. 2493-2502, Jul.-Aug. 2014

[11] S. Shin, J. Kim, S.B. Lee, C. Lim, E. Wiedenbrug, "Evaluation of the influence of rotor magnetic anisotropy on condition monitoring of 2 pole induction motors," Proc. IEEE ECCE, pp. 638-645, Sept. 2014.

[12] M. Riera-Guasp, J. A. Antonino-Daviu, M. Pineda-Sanchez, R. PuchePanadero, and J. Perez-Cruz, "A General Approach for the Transient Detection of Slip-Dependent Fault Components Based on the Discrete Wavelet Transform," IEEE Trans. Ind. Electron., vol. 55, pp. 41674180, 2008.

[13] J. Antonino-Daviu, M. Riera-Guasp, J. Pons-Llinares, Jongbin Park, Sang Bin Lee, Jiyoon Yoo and C. Kral, "Detection of Broken OuterCage Bars for Double-Cage Induction Motors Under the Startup Transient," IEEE Trans. Ind. Appl., , vol.48, no.5, pp.1539,1548, Sept.Oct. 2012

[14] H. Douglas, P. Pillay, and A. K. Ziarani, "A new algorithm for transient motor current signature analysis using wavelets," IEEE Trans. Ind. Appl., vol. 40, no.5, pp. 1361-1368, Sep./Oct. 2004.

[15] S.H. Kia, H. Henao, G.A. Capolino, "Diagnosis of Broken-Bar Fault in Induction Machines Using Discrete Wavelet Transform Without Slip Estimation," IEEE Trans. Ind. Appl., vol.45, no.4, pp.1395-1404, Julyaug. 2009

[16] R. Supangat, N. Ertugrul, W. L. Soong, D. A. Gray, C. Hansen, and J. Grieger, "Detection of broken rotor bars in induction motor using starting-current analysis and effects of loading," IEE Proc. Electr. Power Appl., vol. 153, no. 6, pp. 848-855, Nov. 2006.

[17] Y. Gritli, C. Rossi, L. Zarri, F. Filippetti, A. Chatti, D. Casadei and A Stefani, "Advanced diagnosis of broken bar fault in induction machines by using Discrete Wavelet Transform under time-varying condition," 2011 IEEE International Electric Machines \& Drives Conference (IEMDC), vol., no., pp.424-429, 15-18 May 2011

[18] F. Briz, M.W. Degner, J. M. Guerrero, and P. García, " Stator Windings Fault Diagnostics of Induction Machines Operated From Inverters and Soft-Starters Using High-Frequency Negative-Sequence Currents," IEEE Transactions on Industry Applications, , vol.45, no.5, pp.1637,1646, Sept.-Oct. 2009.

[19] J. Pons-Llinares, J. Antonino-Daviu, M. Riera-Guasp, S.B. Lee,T. Kang, C. Yang, "Advanced Induction Motor Rotor Fault Diagnosis via Continuous and Discrete Time-Frequency Tools" IEEE Trans. Ind. Electron. To be published.

[20] G. Georgoulas, I.P. Tsoumas, I.P., J.A. Antonino-Daviu, V. ClimenteAlarcon, C.D Stylios, E.D. Mitronikas, and A.N. Safacas, "Automatic Pattern Identification Based on the Complex Empirical Mode Decomposition of the Startup Current for the Diagnosis of Rotor Asymmetries in Asynchronous Machines" IEEE Trans. Ind. Electron., vol. 55, pp. 4937-4946, Sep. 2014.

[21] B. Xu, L. Sun, L. Xu, G. Xu, «Improvement of the Hilbert Method via ESPRIT for Detecting Rotor Fault in Induction Motors at Low Slip », 
IEEE Transactions On Energy Conversion, Vol. 28, No. 1, Pp. 225233, March 2013.

[22] Y. Gritli, L. Zarri, C. Rossi, F. Filippetti, G. Capolino, and D. Casadei, "Advanced diagnosis of electrical faults in wound rotor induction machines," IEEE Trans. Ind. Electron., vol. 60, no. 9, pp. 4012-4024, Sep. 2013.

[23] V.Climente-Alarcon, J.A. Antonino-Daviu, M. Riera-Guasp, and M. Vlcek, "Induction Motor Diagnosis by Advanced Notch FIR Filters and the Wigner-Ville Distribution", IEEE Trans. Ind. Electron., vol. 61, no. 8, pp.4217-4227, August 2014

[24] G. Georgoulas, M.O. Mustafa, I.P. Tsoumas,J. Antonino-Daviu, V. Climente-Alarcon, C.D. Stylios, G. Nikolakopoulos, "Principal Component Analysis of the startup transient and Hidden Markov Modeling for broken rotor bar fault diagnosis in asynchronous machines". Expert Systems with Applications, 40(17), 7024-7033, 2013.

[25] Sydney Burrus, Rames A. Gopinath, Haitao Guo. Introduction to Wavelets and Wavelets Transforms. A Primer. 1 edition. Prentice Hall. August 1997.

[26] J. Pons-Llinares, J.A. Antonino-Daviu, M. Riera-Guasp, M. PinedaSanchez and V. Climente-Alarcon, "Induction Motor Diagnosis based on a Transient Current Analytic Wavelet Transform via Frequency BSplines", IEEE Trans. Ind. Electron, vol.58, no.5, pp.1530-1544, May 2011. 